\title{
Pretreatment Levels of Chromogranin A and Neuron-specific Enolase in Patients With Gastroenteropancreatic Neuroendocrine Neoplasia
}

\author{
ŠTEFAN KEČKÉŠ ${ }^{1,2}$, JÚLIUS PALAJ $^{3}$, IVETA WACZULÍKOVÁ ${ }^{4}$, \\ DANIEL DYTTERT ${ }^{3}$, EMÍLIA MOJTOVÁ ${ }^{5}$, GUSTÁV KOVÁČ ${ }^{6}$ and ŠTEFAN DURDÍK ${ }^{2,3}$ \\ ${ }^{1}$ Department of Hematology and Transfusiology, St. Elizabeth Cancer Institute, Bratislava, Slovak Republic; \\ ${ }^{2}$ St. Elizabeth University of Health and Social Sciences, Bratislava, Slovak Republic; \\ ${ }^{3}$ Department of Oncological Surgery, St. Elizabeth Cancer Institute, \\ and Faculty of Medicine in Bratislava of the Comenius University, Bratislava, Slovak Republic; \\ ${ }^{4}$ Department of Nuclear Physics and Biophysics, Faculty of Mathematics, \\ Physics and Informatics, Comenius University, Bratislava, Slovak Republic; \\ ${ }^{5}$ Department of Endocrinology, St. Elizabeth Cancer Institute, Bratislava, Slovak Republic; \\ ${ }^{6}$ Department of Clinical Chemistry, Biochemistry and Laboratory Medicine, \\ Slovak Medical University, Faculty of Medicine, Bratislava, Slovak Republic
}

\begin{abstract}
Background/Aim: Chromogranin A $(\mathrm{CgA})$ and neuron-specific enolase (NSE) are applied in the diagnosis of neuroendocrine neoplasms (NENS), especially non-functional ones. The aim of this study was to investigate the predictive values of CgA and NSE in long-term survival. Patients and Methods: Our retrospective analysis included 65 patients with histologically verified gastroenteropancreatic NEN between 2005 and 2019. We performed bivariate and multivariable analyses to evaluate the relationship between CgA and NSE values before histological assessment and overall survival. Distribution of time-to-event was analyzed using KaplanMeier survival curves and modelled by Cox regression models. Results: Elevated NSE levels prior to histology were significantly associated with worse survival (HR=1.13, $p=0.004)$ and were associated with low-differentiated NENs $\left(r_{s}=0.321, p=0.0338\right) . C g A$ was associated with welldifferentiated tumors $\left(r_{s}=0.233\right)$, but not significantly. Conclusion: Pretreatment serum levels of NSE can serve as
\end{abstract}

This article is freely accessible online.

Correspondence to: Dr. Štefan Kečkéš, Department of Hematology and Transfusiology, St. Elizabeth Cancer Institute, Heydukova 10, 81250 Bratislava, Slovak Republic. Tel: +421 915389965, Fax: +421 252923711, e-mail: stefan.keckes@ousa.sk

Key Words: Neuroendocrine neoplasia, NET, chromogranin A, neuron-specific enolase, NSE. a valuable additional predictor of long-term survival in patients with NEN.

Neuroendocrine neoplasms (NEN) derived from neuroendocrine (NE) cells form a heterogeneous group of neoplasms with a wide range of morphological, functional and biological properties. NENs can essentially occur in all body organs, even in those where NE cells are not usually present. The largest group of NENs are gastroenteropancreatic NENs (GEP-NENs), which account for $70 \%$ of all NEN cases. They are followed by bronchopulmonary (respiratory) NENs (25\%). The remaining $5 \%$ consists of NENs of other organ systems such as thymic, mediastinal or urogenital NENs (1).

Based on the production of a specific endocrine product, NENs can be considered as functional or non-functional. Functional NENs/NETs form bioactive mediators capable of inducing specific clinical syndromes. Non-functional NENs either do not form bioactive products or produce them but do not subsequently excrete them, or they form products that do not cause a specific clinical syndrome (e.g., pancreatic polypeptide). In the case of pancreatic NENs, up to $30 \%$ are formed by functional neoplasms. Other gastrointestinal NENs are functional in 3-13\% of cases (2). Both functional and non-functional NETs can produce and secrete into the circulation proteins specific for cells with NE differentiation. Some of them are used as tumor markers aiding in diagnosis and monitoring and acting as prognostic markers. The most widely used non-specific markers of NENs are chromogranin $\mathrm{A}(\mathrm{CgA})$ and neuron-specific enolase (NSE). 
Chromogranin A $(\mathrm{CgA})$ is a hydrophilic, acidic glycoprotein present in large secretory vesicles of NE cells. Its polypeptide chain consists of 439 amino acids (49 kD) (3). $\mathrm{CgA}$ is secreted into the circulation together with monoamines and peptides. Circulating $\mathrm{CgA}$ is a universal marker of both functional and non-functional NENs. CgA can be determined in both serum and plasma, whereas plasma values are slightly higher. Fasting and rest are necessary before specimen collection, as food intake or exercise increases $\mathrm{CgA}$ levels. Proton pump inhibitors (PPIs) should be discontinued for 7 days, if the patient clinical condition allows it, and should be replaced with $\mathrm{H} 2$ blockers which should be discontinued $24 \mathrm{~h}$ before blood collection (4). Since somatostatin analogues block the production and secretion of $\mathrm{CgA}$, it is recommended to take blood samples at the same time interval after administration of the analogue (4).

Several oncological and non-oncological diseases increase $\mathrm{CgA}$ levels, which can lead to false-positivity with respect to NEN. Because hypergastrinemia causes hyperplasia of CgA-producing enterochromaffin-like cells, all conditions associated with hypergastrinemia are also associated with $\mathrm{CgA}$ elevation (5). Actually, all gastrinomas have elevated $\mathrm{CgA}$ even in the absence of metastases. Overall, 30-50\% of $\mathrm{NEN}$ s have $\mathrm{CgA}$ values within the reference ranges. $\mathrm{CgA}$ sensitivity is acceptable for secretory active, functional and advanced NENs (50-70\%). Not only basal levels of CgA are clinically relevant, but also their changes over time. According to Chou et al. (2012, 2014), CgA levels are associated with treatment response in patients with GEPNENs $(6,7), \mathrm{CgA}$ is usually positive in the presence of liver metastases, but in this indication it is rather an additional diagnostic modality to more specific markers, imaging tests and biopsies (8). Sensitivity is insufficient for localized nonfunctional tumors that have normal $\mathrm{CgA}$ levels in approximately $70 \%$ of cases (9). Aggressive, lowdifferentiated carcinomas with lower number of secretory vesicles may also be false-negative (4).

It is assumed that the main clinical utility of $\mathrm{CgA}$ is determination of patient prognosis and stratification. The RADIANT-2 study, which examined the efficacy of combined therapy with everolimus and long-acting release octreotide in patients with advanced NENs, confirmed that low levels of $\mathrm{CgA}$ are a positive prognostic marker of overall survival regardless of the type of administered treatment $(\mathrm{HR}=0.31$, 95\% CI $=0.23-0.42, p<0.001)(10)$. The CLARINET study with lanreotide confirmed that a decrease in $\mathrm{CgA}$ levels is associated with reduced risk of disease progression (11).

Neuron-specific enolase (NSE) is a cell-specific isoenzyme of the glycolysis and gluconeogenesis enzyme. Expression of NSE is a late step in neural differentiation characteristic of neurons and NE cells (12). Because NSE is expressed in erythrocytes, hemolytic serum causes false positivity. NSE levels are not dependent on tumor secretory activity. Elevation of NSE may occur during treatment due to increased cell turnover and release of NSE into the circulation. According to the study of Baudin, the sensitivity of NSE for GEP-NENs was 39\%. In contrast to CgA, NSE was associated with low-differentiated NENs (13).

The primary objective of this study was, therefore, to investigate the predictive value of pretreatment levels of $\mathrm{CgA}$ and NSE for NEN detection prior to histology. A secondary aim was to explore their association with longterm outcomes.

\section{Patients and Methods}

Clinical data of patients were obtained from the registry of the Oncological Institute of St. Elizabeth in Bratislava. Inclusion criteria were: histologically verified GEP-NEN with disease grading based on WHO classification. The 2010 classification was used for gastrointestinal NENs (14) and the 2017 classification for pancreatic NENs (15). Specimen sent for histologization was collected as a part of an endoscopic examination, radical or palliative resection, or metastasectomy. Levels of CgA and NSE were examined using standard laboratory protocols in samples taken from patients a day to four weeks prior to histology, between 2005 and 2019. However, $\mathrm{CgA}$ and NSE levels were not available in all patients. In addition, other information was included such as tumor grading, age at the time of histology, and patient sex.

Using descriptive statistics, we evaluated the relative proportions of tumor sites within GEP-NENs. Bivariate analyzes evaluated the statistical association of gender, age, CgA, NSE, and grading with overall patient survival. Subsequently, we evaluated the influence of individual variables on overall survival by multivariate analysis Cox proportional hazards model. We used Kaplan-Meier survival curves to assess the survival of patients in individual groups divided by CgA, NSE and grading. All listed probability values ( $p$-value) are two-tailed. The value of statistical significance was chosen at the level of $p<0.05$. We used Microsoft Excel 2013, a statistical Excel Add-in BESH, Stat version 0.09 (http://beshstat.eu), and IBM SPSS.

\section{Results}

A total of 65 patients, 30 men (46.2\%) and 35 women $(53.8 \%)$ were enrolled in the study. The most common localizations of NENs were small intestine (34\%) and pancreas $(30 \%)$. They were followed by histological examination of metastases $(11 \%)$, colorectum $(11 \%)$, stomach $(8 \%)$, ampullary region and papilla of Vater $(5 \%)$, ileocecal region $(1 \%)$.

Bivariate analysis. Of the total number of 65 patients, CgA was examined in $49(75.4 \%)$ and NSE in $44(67.7 \%)$ patients. Both markers were determined in 39 patients $(60.0 \%)$. Demographic data such as gender and age are summarized in Table I, along with grading and the results of bivariate analyses. We verified the individual correlations between variables: $\mathrm{CgA}$, NSE, age (continuous variables), 
Kečkéš et al: Neuroendocrine Serum Tumor Markers

Table I. Clinical and laboratory characteristics of 65 patients with NEN treated between 2005 and 2019 - grouped by primary outcome.

\begin{tabular}{|c|c|c|c|c|c|}
\hline $\begin{array}{l}\text { Patient characteristics } \\
\text { Number }\end{array}$ & & $\begin{array}{c}\text { Total } \\
\mathrm{n}=65(100 \%)\end{array}$ & $\begin{array}{c}\text { Dead } \\
\mathrm{n}=19(100 \%)\end{array}$ & $\begin{array}{c}\text { Survived } \\
\mathrm{n}=46(100 \%)\end{array}$ & $p$-Value \\
\hline Age (years) & Mean \pm SD & $58.1 \pm 11.19$ & $60.8 \pm 10.73$ & $56.9 \pm 11.29$ & 0.2788 \\
\hline \multirow[t]{2}{*}{ Gender } & Male & $30(46.2 \%)$ & $9(47.4 \%)$ & $21(45.7 \%)$ & 0.8995 \\
\hline & Female & $35(53.8 \%)$ & $10(52.6 \%)$ & $25(54.3 \%)$ & \\
\hline \multirow[t]{3}{*}{ Grading } & Grade 1 & $36(55.4 \%)$ & $8(42.1 \%)$ & $28(60.9 \%)$ & 0.0086 \\
\hline & Grade 2 & $18(27.7 \%)$ & $3(15.8 \%)$ & $15(32.6 \%)$ & \\
\hline & Grade 3 & $11(16.9 \%)$ & $8(42.1 \%)$ & $3(6.5 \%)$ & \\
\hline Patient characteristics & & Total & Dead & Survived & $p$-Value \\
\hline Number & & $\mathrm{n}=49(75.4 \%)$ & $\mathrm{n}=16(84.2 \%)$ & $\mathrm{n}=33(71.7 \%)$ & \\
\hline \multirow[t]{2}{*}{$\mathrm{CgA}(\mathrm{ng} / \mathrm{ml})$} & $\geq 102$ & $25(51.0 \%)$ & $11(68.8 \%)$ & $14(42.4 \%)$ & 0.0839 \\
\hline & $<102$ & $24(49.0 \%)$ & $5(31.3 \%)$ & $19(57.6 \%)$ & \\
\hline Patient characteristics & & Total & Dead & Survived & $p$-Value \\
\hline Number & & $\mathrm{n}=44(67.7 \%)$ & $\mathrm{n}=13(68.4 \%)$ & $\mathrm{n}=31(67.4 \%)$ & \\
\hline \multirow[t]{2}{*}{ NSE (ng/ml) } & $\geq 12.5$ & $19(43.2 \%)$ & $10(76.9 \%)$ & $9(29.0 \%)$ & 0.0034 \\
\hline & $<12.5$ & $25(56.8 \%)$ & $3(23.1 \%)$ & $22(71.0 \%)$ & \\
\hline
\end{tabular}

NEN: Neuroendocrine neoplasia; n: number; CgA: chromogranin A; NSE: neuron-specific enolase. Bold values represent statistical significance.

grading (ordinal) and expressed them with a nonparametric correlation coefficient (Spearman's $\mathrm{r}_{\mathrm{s}}$ ) as shown in Table II.

A lower age was associated with a higher tumor grading, the correlation was statistically significant, but the relationship was weak. A significant, moderate relationship between NSE levels and grading was confirmed $\left(r_{\mathrm{s}}=0.321\right)$, NSE elevation was associated with low-differentiated NENs. In contrast, elevated $\mathrm{CgA}$ associates with well-differentiated tumors $\left(\mathrm{r}_{\mathrm{s}}=-0.233\right)$, but this relationship was weak and statistically not significant. The coefficient Eta $(\eta)$ expressing the relationship between gender and continuous variables $\mathrm{CgA}, \mathrm{NSE}$ and age was $\eta=0.012$, 0.328 , and 0.047 , respectively. Thus, a moderately significant relationship between gender and NSE was confirmed (the other two relationships are negligible), which we further analyzed in a multivariate analysis. The contingency coefficient $(\mathrm{Vc}=0.171)$ between patient sex and tumor grading indicates only a negligible and statistically insignificant relationship.

Using the Pearson's Chi-square test, we verified the relationship between the overall patient survival and $\mathrm{CgA}$, NSE, age, respectively. CgA and NSE were dichotomized according to reference values (CgA: $102 \mathrm{ng} / \mathrm{ml}$, NSE: 12.5 $\mathrm{ng} / \mathrm{ml}$ ) and processed as nominal variables. Elevated levels of NSE are statistically significantly associated with worse survival ( $p=0.0034)$. Regarding $\mathrm{CgA}$ elevation, the association was approaching the level of significance $(p=0.0839)$. The Cochran-Armitage's test confirmed the statistical relationship between patient survival and tumor grading ( $p=0.0086)$. The results of the bivariate analyzes expressed by the $p$-values are summarized in Table I.
Table II. Correlations between variables: CgA, NSE, age (continuous) and grading (ordinal).

\begin{tabular}{llcccc}
\hline & & Age & CgA & NSE & Grade \\
\hline Age & Rho $\left(\mathrm{r}_{\mathrm{s}}\right)$ & 1.000 & & & \\
& $p$-Value & $\mathrm{N} / \mathrm{A}$ & & & \\
& $\mathrm{n}$ & 65 & & & \\
CgA & Rho $\left(\mathrm{r}_{\mathrm{s}}\right)$ & 0.198 & 1.000 & & \\
& $p$-Value & 0.173 & $\mathrm{~N} / \mathrm{A}$ & & \\
& $\mathrm{n}$ & 49 & 49 & & \\
NSE & Rho $\left(\mathrm{r}_{\mathrm{s}}\right)$ & -0.036 & 0.198 & 1.000 & \\
& $p$-Value & 0.815 & 0.226 & $\mathrm{~N} / \mathrm{A}$ & \\
& $\mathrm{n}$ & 44 & 39 & 44 & \\
Grade & Rho $\left(\mathrm{r}_{\mathrm{s}}\right)$ & $\mathbf{- 0 . 2 7 7}$ & -0.233 & $\mathbf{0 . 3 2 1}$ & 1.000 \\
& $p$-Value & $\mathbf{0 . 0 2 5}$ & 0.107 & $\mathbf{0 . 0 3 3}$ & $\mathrm{N} / \mathrm{A}$ \\
& $\mathrm{n}$ & $\mathbf{6 5}$ & 49 & $\mathbf{4 4}$ & 65 \\
\hline
\end{tabular}

n: Number; CgA: chromogranin A; NSE: neuron-specific enolase; Rho $\left(r_{\mathrm{s}}\right)$ : Spearman's rank correlation coefficient; N/A: not applicable. Bold values represent statistical significance.

Multivariable analysis. We used a standard Cox proportional hazards models to test the effect of the levels of tumor markers CgA and NSE (as continuous variables), age, sex, and grading on the long-term survival of patients with GEP-NEN. According to the results of Kaplan-Meier analyses we decided to merge G1 and G2 group with similar survival curves. This decision is also supported by the findings of Klöppel (1). In the full model adjusted for age and sex, the variable $\mathrm{CgA}$ was not found statistically 
Table III. Multivariable Cox regression analysis of factors associated with overall survival in patients with NEN.

\begin{tabular}{|c|c|c|c|c|}
\hline Variable & $\mathrm{b}$ & $p$-Value & HR & $95 \% \mathrm{CI}$ \\
\hline \multicolumn{5}{|l|}{ Gender } \\
\hline Female & Reference & & 1 & \\
\hline Male & 1.1189 & 0.1655 & 3.061 & $0.630-14.881$ \\
\hline $\begin{array}{l}\text { Age at } \\
\text { histologization } \\
\text { (years) }\end{array}$ & 0.0384 & 0.2731 & 1.039 & $0.970-1.113$ \\
\hline NSE (ng/ml) & 0.1193 & 0.0044 & 1.127 & $1.038-1.223$ \\
\hline Grade 1 or 2 & Reference & & 1 & \\
\hline Grade 3 & 2.0487 & 0.0262 & 7.758 & $1.274-47.247$ \\
\hline
\end{tabular}

The likelihood $\chi^{2}$ test statistic was 23.9 and corresponding $p<0.001$. NEN: Neuroendocrine neoplasia; P: probability; b: regression coefficients; HR: hazard ratio; 95\% CI: 95\% confidence interval; $\mathrm{CgA}$ : chromogranin A; NSE: neuron-specific enolase. Bold values represent statistical significance.

significant, thus, it did not make an additional contribution to the risk of death over and above that of other variables (data not shown).

The variables NSE and grading, that were identified as statistically significant by bivariate analyzes, remained significant also in the multiple regression analysis. The final model built from four variables: age, sex, NSE and grading was statistically significant; the value of test statistic $\chi^{2}$ reached the value 23.9 and the respective $p<0.001$. The regression coefficient results of the Cox model and computed HRs adjusted for the other predictors are summarized in Table III.

Survival analysis. To visualize the association of survival with CgA, NSE (as nominal variables), or grading (ordinal variable), we performed a Kaplan-Meier analysis. Visually more pronounced differences between the curves for NSE versus $\mathrm{CgA}$ confirm the greater importance of NSE elevation in the overall survival of patients (Figure 1, upper and middle part). By evaluating the survival curves for the grading stages, it can be stated that patients with G3 tumors had the worst survival. Survival of patients with G1 and G2 tumors was comparable, paradoxically patients with G2 grading survived best. By the 53rd month, patients with G1 tumors had better survival compared with the G2 group. Subsequently, the survival curves of the G1 and G2 groups cross, and more favorable survival of $\mathrm{G} 2$ group is achieved until the end of follow-up (Figure 1, lower part).

\section{Discussion}

NENs form a heterogeneous group of malignancies that arise from neuroendocrine cells throughout the body. They most commonly occur in gastrointestinal and respiratory tract, but
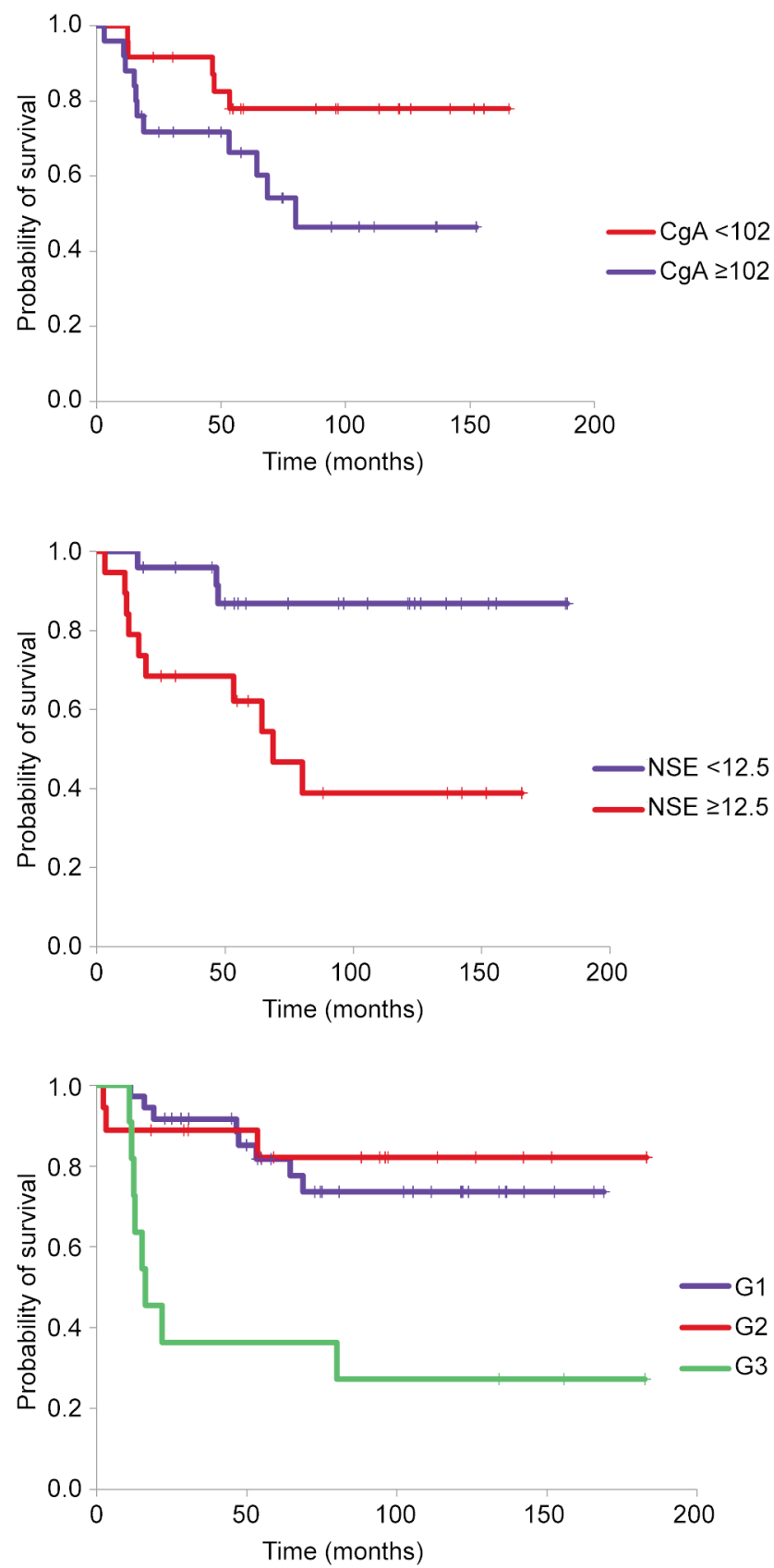

Figure 1. Kaplan-Meier curves for overall survival in patients with NEN grouped by level of $\mathrm{CgA}$ (upper part, levels of $102 \mathrm{ng} / \mathrm{ml}$ or above were considered elevated, overall log rank test: $p=0.070$ ), NSE (middle part, levels of $12.5 \mathrm{ng} / \mathrm{ml}$ or above were considered elevated, overall log rank test: $p=0.003$ ), and tumor grading (lower part, overall log rank test: $p=0.001$ ).

may also develop in other organs (e.g., endocrine glands, mediastinum, and skin). These tumors differ significantly in their malignant potential. The unifying element of this group is the evidence of NE differentiation. Functional NENs 
synthesize specific bioactive mediators such as serotonin, histamine, insulin, gastrin and many others, which causes a faster clinical manifestation and thus faster and more specific laboratory diagnostics. Non-functional NENs clinically manifest by local symptoms caused by tumor growth and dissemination, which significantly delays the diagnosis. Late diagnosis is undoubtedly one of the major causes of high mortality in non-functional low-differentiated NE carcinomas.

The most commonly used non-specific markers of NENs are $\mathrm{CgA}$ and NSE, whereas most data on their sensitivity and specificity are from retrospective studies. CgA sensitivity differs significantly between studies (24-88\%) (9). The diversity of results is mainly caused by different tumor locations, the extent of disease and differences in immunochemical analyses. An exception to the retrospective studies on $\mathrm{CgA}$ are the prospective RADIANT-2 and CLARINET studies. The RADIANT-2 study confirmed that low levels of circulating $\mathrm{CgA}$ were a statistically independent predictor of long-term survival, and the CLARINET study confirmed that decrease in $\mathrm{CgA}$ levels are associated with a lower risk of disease progression $(10,11)$. ENETS and NCCN guidelines recommend measuring CgA levels, the use of NSE is not mentioned in the current guidelines $(16,17)$. In general, NSE is considered to be a less useful marker of NENs than CgA (13).

In our group of patients with GEP-NENs, NSE appears to be a more suitable marker of long-term survival. Statistical significance was confirmed not only in the bivariate but also in the multivariate analysis (Tables I and II). Consistent with published studies (13), NSE is associated with worse grading $\left(\mathrm{r}_{\mathrm{s}}=0.3213, p=0.0338\right)$. In contrast, $\mathrm{CgA}$ is associated with well-differentiated tumors $\left(\mathrm{r}_{\mathrm{s}}=-0.2331\right)$, but not statistically significant. As mentioned in the study by Klöppel et al. (2017) (1), NENs of different localizations can be dichotomously divided into well-differentiated (G1 and G2) and low-differentiated neoplasms (G3) (1). The results of the Kaplan-Meier survival analysis stratified by grading showed that the curves for G1 and G2 groups significantly overlapped (Figure 1, lower part). Overall, in comparison with patients having well-differentiated NEN survival was reduced for patients with low-differentiated NEN ( $p=0.001)$, which is consistent with previously published literature (18, 19). The G3 group yielded significantly worse survival also in the multivariable analysis after adjusting for age, sex and NSE levels $(\mathrm{HR}=7.76, p=0.026)$.

As early diagnosis of low-differentiated tumors, often with lower secretory vesicles, is crucial, NSE appears to be a more appropriate marker for malignant NENs and should be part of the initial biochemical examination when NEN is suspected. In our study, $51.0 \%$ and $43.2 \%$ of patients had elevated CgA and NSE levels, respectively. Of those who had both markers examined, $74.3 \%$ had at least one marker elevated. We assume that the combination of both markers significantly increases the sensitivity of NEN detection. Due to the retrospective nature of the study and the absence of a randomization and control cohort, our conclusions need to be further verified by prospective studies.

$\mathrm{CgA}$ and NSE represent completely different proteins; $\mathrm{CgA}$ is dependent on tumor secretory activity, while the NSE is dependent on cell turnover. However, both markers represent features of neuroendocrine differentiation, which is the cornerstone of all NENs. Despite the relatively rare occurrence of NENs, any elevation in CgA and NSE levels should be closely investigated. Until modern non-invasive molecular methods such as NETest $(20,21)$ come into routine practice, $\mathrm{CgA}$ and NSE have their place in the laboratory diagnostics of NEN.

\section{Conclusion}

Pre-treatment serum NSE levels can serve as a marker of long-term survival in patients with NENs. NSE is associated with malignant forms of NEN with higher grading. In contrast, $\mathrm{CgA}$ is a marker of well-differentiated NENs. We assume that by combining these two markers we can achieve an increased sensitivity of NEN detection.

\section{Conflicts of Interest}

Štefan Kečkéš, Július Palaj, Iveta Waczulíková, Daniel Dyttert, Emília Mojtová, Gustáv Kováč, Štefan Durdík have no conflicts of interest or financial ties to disclose.

\section{Authors' Contributions}

Š.K., D.D. and E.M. contributed to the conception and design. G.K. and Š.D. were responsible for overall supervision, $\breve{S}$.K and I.W. for statistical analysis, Š.K. and D.D. drafted the manuscript, which was revised by I.W. and Š.D. All Authors read and approved the final manuscript.

\section{Acknowledgements}

The study was partially supported by the Grant KEGA 041UK$4 / 2020$.

\section{References}

1 Klöppel G: Neuroendocrine neoplasms: Dichotomy, origin and classifications. Visc Med 33(5): 324-330, 2017. PMID: 29177160. DOI: $10.1159 / 000481390$

2 Ito $\mathrm{T}$, Lee $\mathrm{L}$ and Jensen RT: Treatment of symptomatic neuroendocrine tumor syndromes: recent advances and controversies. Expert Opin Pharmacother 17(16): 2191-2205, 2016. PMID: 27635672. DOI: 10.1080/14656566.2016.1236916

3 Deftos LJ: Chromogranin A: its role in endocrine function and as an endocrine and neuroendocrine tumor marker. Endocr Rev 12(2): 181-187, 1991. PMID: 2070778. DOI: 10.1210/edrv-122-181 
4 Gut P, Czarnywojtek A, Fischbach J, Bączyk M, Ziemnicka K Wrotkowska E, Gryczyńska M and Ruchała M: Chromogranin A - unspecific neuroendocrine marker. Clinical utility and potential diagnostic pitfalls. Arch Med Sci 12(1): 1-9, 2016. PMID: 26925113. DOI: 10.5114/aoms.2016.57577

5 Kuipers EJ: Proton pump inhibitors and gastric neoplasia. Gut 55(9): 1217-1221, 2006. PMID: 16905689. DOI: 10.1136/ gut.2005.090514

6 Chou WC, Hung YS, Hsu JT, Chen JS, Lu CH, Hwang TL, Rau $\mathrm{KM}$, Yeh KY, Chen TC and Sun CF: Chromogranin A is a reliable biomarker for gastroenteropancreatic neuroendocrine tumors in an Asian population of patients. Neuroendocrinology 95(4): 344-350, 2012. PMID: 22343505. DOI: 10.1159/ 000333853

7 Chou WC, Chen JS, Hung YS, Hsu JT, Chen TC, Sun CF, Lu $\mathrm{CH}$ and Hwang TL: Plasma chromogranin A levels predict survival and tumor response in patients with advanced gastroenteropancreatic neuroendocrine tumors. Anticancer Res 34(10): 5661-5669, 2014. PMID: 25275071.

8 Jensen RT, Cadiot G, Brandi ML, de Herder WW, Kaltsas G, Komminoth P, Scoazec JY, Salazar R, Sauvanet A, Kianmanesh $\mathrm{R}$ and Barcelona Consensus Conference participants: ENETS Consensus Guidelines for the management of patients with digestive neuroendocrine neoplasms: functional pancreatic endocrine tumor syndromes. Neuroendocrinology 95(2): 98-119, 2012. PMID: 22261919. DOI: 10.1159/000335591

9 Jilesen AP, Busch OR, van Gulik TM, Gouma DJ and Nieveen van Dijkum EJ: Standard pre- and postoperative determination of chromogranin a in resectable non-functioning pancreatic neuroendocrine tumors - diagnostic accuracy: NF-pNET and low tumor burden. Dig Surg 31(6): 407-414, 2014. PMID: 25572908. DOI: $10.1159 / 000370007$

10 Pavel ME, Baudin E, Öberg KE, Hainsworth JD, Voi M, Rouyrre N, Peeters M, Gross DJ and Yao JC: Efficacy of everolimus plus octreotide LAR in patients with advanced neuroendocrine tumor and carcinoid syndrome: final overall survival from the randomized, placebo-controlled phase 3 RADIANT-2 study. Ann Oncol 28(7): 1569-1575, 2017. PMID: 28444114. DOI: $10.1093 /$ annonc/mdx 193

11 Buil-Bruna N, Dehez M, Manon A, Nguyen TX and Trocóniz IF: Establishing the quantitative relationship between Lanreotide Autogel ${ }^{\circledR}$, Chromogranin A, and progression-free survival in patients with nonfunctioning gastroenteropancreatic neuroendocrine tumors. AAPS J 18(3): 703-712, 2016. PMID: 26908127. DOI: $10.1208 / \mathrm{s} 12248-016-9884-3$

12 Isgrò MA, Bottoni $\mathrm{P}$ and Scatena R: Neuron-specific enolase as a biomarker: Biochemical and clinical aspects. Adv Exp Med Biol 867: 125-143, 2015. PMID: 26530364. DOI: 10.1007/97894-017-7215-0_9

13 Baudin E, Gigliotti A, Ducreux M, Ropers J, Comoy E, Sabourin JC, Bidart JM, Cailleux AF, Bonacci R, Ruffié P and Schlumberger M: Neuron-specific enolase and chromogranin A as markers of neuroendocrine tumours. Br J Cancer 78(8): 11021107, 1998. PMID: 9792158. DOI: 10.1038/bjc.1998.635
14 Scoazec JY, Couvelard A and pour le réseau TENpath (réseau national d'expertise pour le diagnostic anatomopathologique des tumeurs neuroendocrines malignes de l'adulte, sporadiques et familiales): [The new WHO classification of digestive neuroendocrine tumors]. Ann Pathol 31(2): 88-92, 2011. PMID: 21601112. DOI: $10.1016 /$ j.annpat.2011.01.001

15 Inzani F, Petrone G and Rindi G: The new World Health Organization classification for pancreatic neuroendocrine neoplasia. Endocrinol Metab Clin North Am 47(3): 463-470, 2018. PMID: 30098710. DOI: 10.1016/j.ecl.2018.04.008

16 O'Toole D, Grossman A, Gross D, Delle Fave G, Barkmanova J, O'Connor J, Pape UF, Plöckinger U, Mallorca Consensus Conference participants and European Neuroendocrine Tumor Society: ENETS Consensus Guidelines for the Standards of Care in Neuroendocrine Tumors: biochemical markers. Neuroendocrinology 90(2): 194-202, 2009. PMID: 19713711. DOI: $10.1159 / 000225948$

17 Kulke MH, Shah MH, Benson AB 3rd, Bergsland E, Berlin JD, Blaszkowsky LS, Emerson L, Engstrom PF, Fanta P, Giordano T, Goldner WS, Halfdanarson TR, Heslin MJ, Kandeel F, Kunz PL, Kuvshinoff BW $2^{\text {nd }}$, Lieu C, Moley JF, Munene G, Pillarisetty VG, Saltz L, Sosa JA, Strosberg JR, Vauthey JN, Wolfgang C, Yao JC, Burns J, Freedman-Cass D and National comprehensive cancer network: Neuroendocrine tumors, version 1.2015. J Natl Compr Canc Netw 13(1): 78-108, 2015. PMID: 25583772. DOI: 10.6004/jncen.2015.0011

18 Grillo F, Albertelli M, Annunziata F, Boschetti M, Caff A, Pigozzi S, Ferone D and Mastracci L: Twenty years of gastroenteropancreatic neuroendocrine tumors: is reclassification worthwhile and feasible? Endocrine 53(1): 58-62, 2016. PMID: 26362059. DOI: 10.1007/s12020-015-0734-3

19 Yang M, Ke NW, Zhang Y, Zeng L, Tan CL, Zhang H, Mai G, Tian BL and Liu XB: Survival analyses for patients with surgically resected pancreatic neuroendocrine tumors by World Health Organization 2010 grading classifications and American joint committee on cancer 2010 staging systems. Medicine (Baltimore) 94(48): e2156, 2015. PMID: 26632896. DOI: 10.1097/MD.0000000000002156

20 Malczewska A, Kos-Kudła B, Kidd M, Drozdov I, Bodei L, Matar S, Oberg K and Modlin IM: The clinical applications of a multigene liquid biopsy (NETest) in neuroendocrine tumors. Adv Med Sci 65(1): 18-29, 2020. PMID: 31841822. DOI: 10.1016/j.advms.2019.10.002

21 Pavel M, Jann H, Prasad V, Drozdov I, Modlin IM and Kidd M: NET blood transcript analysis defines the crossing of the clinical rubicon: When stable disease becomes progressive. Neuroendocrinology 104(2): 170-182, 2017. PMID: 27078712. DOI: $10.1159 / 000446025$ References 